\title{
Energy analysis of a wood or pellet stove in a single-family house equipped with gas boiler and radiators
}

\author{
Marco Marigo $(\varangle)$, Fabio Zulli, Sara Bordignon, Laura Carnieletto, Giuseppe Emmi, Michele De Carli \\ Department of Industrial Engineering - Applied Physics Section, University of Padova, Via Venezia 1 - 35131, Padova, Italy
}

\begin{abstract}
In the residential sector, biomass appliances are widely used for space heating and often combined with other systems. This work aims at comparing the final and primary energy consumption of different configurations, including a conventional and a ducted pellet stove and a wood log stove using air as heat transfer fluid. A dynamic analysis of the interaction between biomass stoves and conventional heating systems, such as gas boilers and radiators, is carried out within a typical single-family house in a mild climate, using TRNSYS software. In addition, natural ventilation of the building is considered using CONTAM, with a focus on external infiltrations and internal air circulation due to the buoyancy effect. Results show that the biomass device in one room promotes the airflows between adjacent thermal zones, enhancing the heat distribution through door openings, in particular when an air ducted stove is present. The final energy consumption resulting from simulations with wood-burning stoves is $21 \%$ higher than pellet stoves. The pellet stove results in similar final energy and a $30 \%$ increase in overall primary energy, while the wood stove increases the final energy by $22 \%$ and approximately $40 \%$ of overall primary energy compared to the case of a traditional gas system coupled to radiators which is considered as reference. Nevertheless, non-renewable primary energy savings are higher than $50 \%$ with pellet stoves and $60 \%$ with wood-log stoves.
\end{abstract}

\author{
Keywords \\ energy model; \\ pellet stove; \\ wood log stove; \\ biomass; \\ CONTAM; \\ TRNSYS
}

\section{Article History \\ Received: 15 September 2021 \\ Revised: 11 December 2021 \\ Accepted: 02 January 2022}

() The Author(s) 2022

\section{Introduction}

\subsection{Background}

The problem of climate change has led, over the years, to an increasing number of policies aimed at saving energy and reducing greenhouse gases (GHG) emissions. The European Commission set ambitious targets in this context, encouraging GHG reduction from $40 \%$ to at least $50 \%$ by 2030 and carbon-neutrality as a benchmark for 2050 (European Commission 2019). Energy savings in households play a crucial role, accounting for $26 \%$ of the global final energy use and about $20 \%$ of the $\mathrm{CO}_{2}$ equivalent emissions. Natural gas is still the most widely used fuel for space heating and domestic hot water production (DHW) (Eurostat 2018). Nevertheless, a recent revision of Directive 2009/28/EC (Renewable Energy Directive) encourages woody biomass use as a possible solution to reach the $32 \%$ renewable share

\footnotetext{
E-mail: marco.marigo@unipd.it
}

target by 2030 (European Parliament and Council 2018). As reported by the European Bioenergy Outlook 2020 (Calderón et al. 2020), only 23\% of the household energy consumption excluding electricity is covered by the share of renewables in 2018, most of which is bioenergy (Carlon et al. 2016). In the Italian context, a technological turnover has influenced the traditional wood-fired devices, whereas pellet devices have grown steadily from $8 \%$ to $22 \%$ between 2010 and 2018 (Francescato and Rossi 2019). The recent success of pellet stoves is due to incentive policies and higher energy density and efficiency compared to wood logs devices (Carvalho et al. 2016; Quinteiro et al. 2019; Gauthier et al. 2020).

Despite the $\mathrm{CO}_{2}$ reduction, a consequence of biomass combustion is the emission of other pollutants. For example, an incomplete combustion process, which is possible especially in the case of firewood, leads to the emission of pollutants such as $\mathrm{CO}, \mathrm{PM}, \mathrm{SO}_{x}, \mathrm{NO}_{x}, \mathrm{NH}_{3}$ (Li et al. 2017). 


\begin{tabular}{|c|c|c|c|}
\hline \multicolumn{4}{|c|}{ List of symbols } \\
\hline$A$ & outer surface $\left[\mathrm{m}^{2}\right]$ & $\eta$ & stove overall efficiency $[\mathrm{W} / \mathrm{W}]$ \\
\hline$C$ & capacitance $[\mathrm{J} / \mathrm{K}]$ & $\tau$ & time constant $[\mathrm{s}]$ \\
\hline$c$ & specific heat capacity $[\mathrm{J} /(\mathrm{kg} \mathrm{K})]$ & & \\
\hline $\mathrm{CF}$ & coverage factor of the heating need $[\mathrm{kWh} / \mathrm{kWh}]$ & \multicolumn{2}{|c|}{ Abbreviations } \\
\hline$E_{\mathrm{P}}$ & primary energy $\left[\mathrm{kWh} /\left(\mathrm{m}^{2}\right.\right.$ year $\left.)\right]$ & & \\
\hline$h$ & heat transfer coefficient $\left[\mathrm{W} /\left(\mathrm{m}^{2} \mathrm{~K}\right)\right]$ & $\begin{array}{l}\mathrm{DHW} \\
\mathrm{DPS}\end{array}$ & domestic hot water \\
\hline IAC & internal air coupling $[\mathrm{kg} / \mathrm{h}]$ & DPS & ducted pellet stove \\
\hline INF & air infiltrations $\left[\mathrm{h}^{-1}\right]$ & $\mathrm{EE}$ & electric energy \\
\hline $\mathrm{LHV}_{\mathrm{s}}$ & lower heating value for solid fuels $[\mathrm{MJ} / \mathrm{kg}]$ & GBR & gas boiler and radiators system \\
\hline $\mathrm{LHV}_{\mathrm{g}}$ & lower heating value for gaseous fuels $\left[\mathrm{MJ} / \mathrm{Sm}^{3}\right]$ & GBR(c) & $\begin{array}{l}\text { gas boiler and radiators system (in case of } \\
\text { staircase door closure) }\end{array}$ \\
\hline $\begin{array}{c}M \\
D\end{array}$ & mass $[\mathrm{kg}]$ & GHG & greenhouse gas \\
\hline$P_{\mathrm{f}}$ & fuel power $[\mathrm{kW}]$ & IAQ & indoor air quality \\
\hline$P_{\min }$ & minimum power output of the stove $[\mathrm{kW}]$ & $\mathrm{PEF}$ & primary energy factor \\
\hline$P_{\mathrm{n}}$ & nominal power of the stove $[\mathrm{kW}]$ & PS & pellet stove \\
\hline$P_{\text {rel }}$ & heat flux released to the environment $[\mathrm{kW}]$ & $\mathrm{PS}(\mathrm{c})$ & pellet stove (in case of staircase door closure) \\
\hline$Q_{\mathrm{d}}$ & $\begin{array}{l}\text { final energy demand for space heating } \\
{\left[\mathrm{kWh} /\left(\mathrm{m}^{2} \text { year }\right)\right]}\end{array}$ & TRY & test reference year \\
\hline$Q_{\text {nd }}$ & energy need for space heating $\left[\mathrm{kWh} /\left(\mathrm{m}^{2}\right.\right.$ year $\left.)\right]$ & WS & wood-log stove \\
\hline$Q_{\text {rel }}$ & heat released to the environment $[\mathrm{J}]$ & \multirow{2}{*}{\multicolumn{2}{|c|}{ Subscripts }} \\
\hline$Q_{\text {res }}$ & space heating residual need $\left[\mathrm{kWh} /\left(\mathrm{m}^{2}\right.\right.$ year $\left.)\right]$ & & \\
\hline$T_{\mathrm{op}}$ & operative temperature $\left[{ }^{\circ} \mathrm{C}\right]$ & nren & non-renewable share \\
\hline$T^{*}$ & external threshold temperature for start-up of the & ren & renewable share \\
\hline & stove $\left[{ }^{\circ} \mathrm{C}\right]$ & s & stove \\
\hline$t$ & time $[\mathrm{s}]$ & $5 \%$ & 5-th percentile \\
\hline$\gamma$ & modulation capacity factor $[\mathrm{W} / \mathrm{W}]$ & $95 \%$ & 95-th percentile \\
\hline
\end{tabular}

These emissions result in significant degradation of air quality; hence the impact of these emissions and the study of alternative fuels are widely discussed topics in literature (Li et al. 2021; Zhao et al. 2021). To this end, Persson et al. $(2005,2009)$ developed a dynamic model based on a detailed $\mathrm{CO}$ emission analysis, simulating a pellet stove or a boiler. On the other hand, many authors also focused on life cycle assessment of biomass heating systems (Caserini et al. 2010; Cespi et al. 2014; Quinteiro et al. 2019).

Biomass appliances use wood logs or pellet as fuel and are divided into two groups: boilers (Haller et al. 2011; Petrocelli and Lezzi 2014; Carlon et al. 2015) and air stoves. The present paper focuses on the last-mentioned solution since it is the most diffused in the market, although boilers can be versatile with different integration such as solar heating (Persson et al. 2019; Krarouch et al. 2020) and new technologies as wood-pellet hybrid stoves (Lamberg et al. 2017).

To properly simulate a stove inside a building, it is essential to consider the thermal inertia of the overall system. On this topic, Georges and Novakovic (2012), Skreiberg and Georges (2018) proposed a single capacitance model to couple the biomass stove with the building in steady-state conditions. Thereby, the heat transfer from the combustion chamber through the stove body can be solved as a one-dimensional heat transfer problem (Schumack 2016). Good model accuracy can also be achieved using a loosely-coupled approach. In this case, the heat released is modelled by applying an internal gain to a specific air-node; therefore, the stove is not physically integrated into the building model. Although such simplification is not valid in the proximity of the stove due to broader vertical temperature gradients, this approach is considered sufficiently accurate for energy purposes (Georges and Novakovic 2012).

Recent papers focused on the potential benefits of a mechanical ventilation system coupled with biomass stoves in passive houses (Feist et al. 2005; Georges and Novakovic 2012; Schumack 2016; Carlon et al. 2016). In contrast, the present work deals with conventional heating systems, i.e. gas boilers and radiators combined with biomass stoves 
fired by wood or pellets. In this context, Elnakat and Gomez (2016) recently conducted a study on the energy consumption of typical households in the US, showing that the use of a wood-log fireplace is widespread and higher than houses with a fully electric heating system.

As for space heating systems, several radiator models can be found in the literature. Tol (2020) investigated the effects of radiator characteristics and operational behaviour by the set-back operation via the thermostatic radiator valves, over-dimensioning of the radiator units. The same author also proposed a new integrated steady-state radiator model. Xu et al. (2008) used a discrete-element and a lumped model to simulate the heating system operation. They used data collected from different case studies to validate and test their model. Pedersen et al. (2019) built a dynamic model in MATLAB, considering the energy stored by water and slowly released into the environment. Finally, a dynamic model for radiators was developed by Holst (1996) in TRNSYS.

Two relevant issues concerning stove oversizing and low modulation capacity have been widely discussed in literature due to their significant influence on the so-called temperature zoning phenomenon, i.e. reaching excessively high temperatures in certain areas within buildings. Generally, it may be mitigated by promoting indoor air circulation through doors' opening (Persson et al. 2005; Georges and Novakovic 2012; Schumack 2016; Skreiberg and Georges 2018; Pedersen et al. 2019). Room overheating can be managed by increasing the capacitance of the stoves, as demonstrated by Carvalho et al. (2013) and Georges et al. (2014), although high heat capacity masonry stoves could be problematic for the complete coverage of the heating demand (Carvalho et al. 2013). However, these papers are related to new well-insulated buildings equipped with mechanical ventilation, which represent a limited number of constructions, while houses with natural ventilation are more common in the existing Italian building stock. In order to properly consider natural ventilation, the most common approaches found in the literature are based on multi-zonal, zonal and CFD models (Yu et al. 2017). CONTAM (Dols and Polidoro 2015) is a widely employed tool for the computational analysis of ventilation and indoor air quality (IAQ) in multi-zonal models of buildings, which has been already validated against measured data (Carvalho et al. 2013; Yu et al. 2017). Therefore, it can be considered a consistent and powerful resource for the dynamic calculation of natural ventilation in buildings (Fine et al. 2020). Usually, this tool requires external air conditions and ambient temperatures to calculate airflow rates. On the other hand, a dynamic energy model of the building allows calculating the internal temperatures and the thermal load by assuming the flow rates. Therefore, the models can be combined to simulate the energy performance of a building with natural ventilation and IAC (McDowell et al. 2003). In the present work, the TRNSYS multi-zonal model was coupled with a model developed using CONTAM. The aim is to investigate the dynamic thermal behaviour of the building and the integrated heating systems, considering infiltrations and natural ventilation through external, internal doors and windows openings, as well as the coupling airflow between adjacent rooms.

The work presented in this paper was carried out within the LIFE PREPAIR project (De Carli et al. 2020), whose aim was to evaluate biomass consumption in the residential sector of the Po Valley, a vast plain in northern Italy. The importance of the study carried out lies in two main aspects: firstly, the high availability of low-cost biomass fuel for residential installations makes these devices very widespread in the considered area; secondly, the high concentration of pollutants in the Po Valley encourages the analysis of the current situation to adopt adequate policies. Several building typologies were analysed using the Italian population and housing census database (ISTAT 2011) to choose a representative "archetype", i.e. a model representing a group of buildings with similar energy performance and geometric characteristics, mainly related to age, heating system, building type and location. It was found that $38 \%$ of the Po Valley building stock consists of single or multifamily houses. Furthermore, the ISTAT survey on households energy consumption showed that residential buildings using biomass as fuel are between $10 \%$ and $15 \%$ in the region considered, most of which are single houses (ISTAT 2013). Low-temperature heating distribution systems are still not often employed in existing buildings, although they are increasingly used in new constructions. On the other hand, existing buildings are mainly equipped with radiators, especially in combination with biomass stoves (Patti et al. 2020). For these reasons, the case study analysed in this paper can be considered representative of an important fraction of the national building stock.

\subsection{Novelty}

The use of dynamic simulations in energy and building sector is crucial, both for new constructions and interventions on existing buildings. This approach, instead of a testbased one, allows detailed analysis of energy use and the definition of targets and future scenarios (Collins 2012). In this context, despite the presence of biomass appliances in nZEB design scenarios, a significant lack of energy analyses related to the presence of biomass burners in residential buildings has been noticed (Harkouss et al. 2018). Although missing information and studies concerning the energy use of biomass burners, they are still widely used in residential 
space heating. The modelling approach to these plants is very detailed and often aimed at analysing heat generation and release into the environment (Cai and Chow 2014; Duanmu et al. 2017).

The model proposed in this paper aims at comparing different plant configurations from the point of view of the energy consumption of the whole building, an issue where there was no evidence of an adequate background. The innovative approach introduced in this paper is based on the combined use of TRNSYS and CONTAM, which allows the evaluation of the heat transfer through the internal air mass movements within the building and the final and primary energy assessment, according to the different types of heating devices and use. The detailed overall dynamic simulation provides significant results for the energy demand covered by biomass stoves, the final energy share and the primary energy potential reductions.

\section{The energy system}

The layout of the energy system, modelled using TRNSYS software, is shown in Figure 1. In the simplified scheme, the different plant components can be identified: they are simulated using one or more TRNSYS elements, named "Types", which are black boxes containing the mathematical models of the system's parts. In detail, the building model is created with the software TRNBuild, represented in the scheme by Type 56 . The building requires some input data, in particular, climatic data fit from a TRY (Type 15-3), internal gains and the ground surface temperature (obtained using Type 77). The coupling with CONTAM is done with Type 97, which allows the evaluation of infiltrations and air couplings. Concerning the gas boiler, the control strategy is mainly done using two thermostats (Type 2) and regulated by a schedule, while the system layout consists of the boiler (Type 751), the supply and return manifolds and the pump. The water heated by the boiler is distributed to radiators modelled through the static Type 1231 and integrated using a lumped capacitance model (Type 963), which allows the modulation of the thermal power released to the room. Also, a control system is implemented in the stove model by combining the stove schedule inputs, the thermostat (Type 1233), and the weather file. The control system gives a feedback to the PID (Type 23), which modulates the stove thermal power output according to a signal $(\gamma)$ that regulates both the air blower (Type 139) and the stove case (Type 963). In this way, by a connection with the building model, the heat is distributed throughout the building respectively with hot air intake and through the heat exchange by natural convection and infrared radiation.

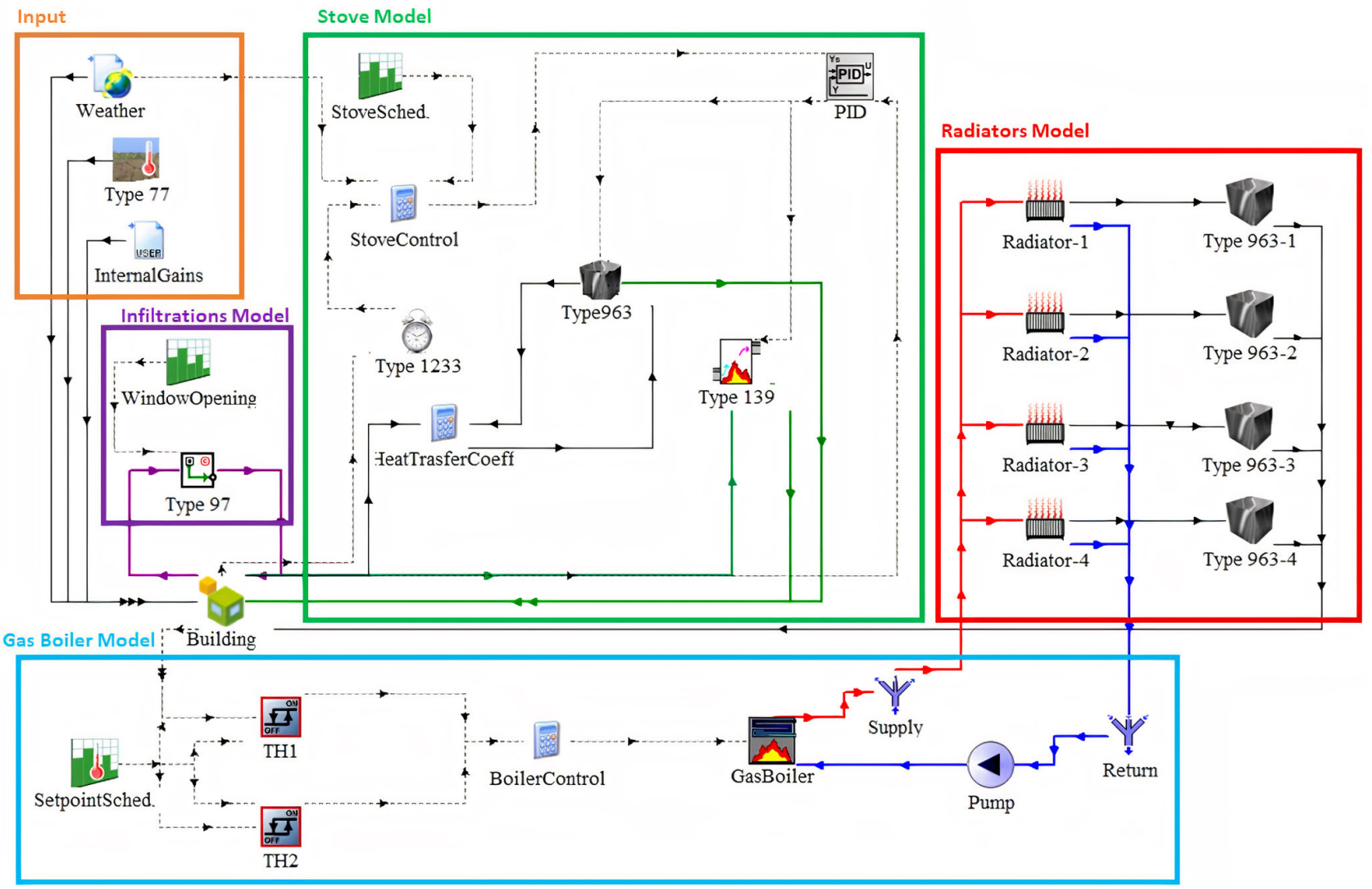

Fig. 1 Scheme of the energy system modelled in TRNSYS 


\subsection{Building model}

The building model was chosen to represent the archetype of a single-family house located in a mild climate area. The building has two floors (each $2.7 \mathrm{~m}$ height) divided into five heated thermal zones, as shown in Figure 2. The area including the living room and kitchen $(\mathrm{Z}-1)$ and the area containing bedrooms (Z-4) are hereafter referred to as day- and night-zone, respectively. According to the Italian Standards (Italian Organisation for Standardisation 2014), the thermal transmittance of each element corresponds to the stratigraphy characteristic of typical houses built in the early 2000s. Vertical walls are assumed to be built in masonry, with a $6 \mathrm{~cm}$ insulation layer; moreover, for both the clay tiled roof and the basement, a $6 \mathrm{~cm}$ layer of insulation was applied. Windows are double-glazed with a wooden frame. The main geometrical characteristics and thermal properties are reported in Table 1. Two unheated thermal zones are also considered in the model: an outdoor garage adjacent to the building and the attic ( $17^{\circ}$ roof slope).

The building was modelled in TRNBuild using a multizonal approach. The air temperature of each thermal zone can be simplified by a single air temperature (air-node) obtained through the well-stirred tank approximation (Klein et al. 2014). Dynamic simulations were carried out on an hourly basis for one year, using the Test Reference Year (TRY) of Venice (Italy) from the EnergyPlus database (https://energyplus.net/weather). The internal gains were defined considering the thermal energy released by people $\left(1.9 \mathrm{~W} / \mathrm{m}^{2}\right.$, assuming 3 inhabitants), appliances $\left(2.4 \mathrm{~W} / \mathrm{m}^{2}\right)$, and lighting $\left(1.1 \mathrm{~W} / \mathrm{m}^{2}\right)$, according to EN 16798-1:2019 (European Committee for Standardization 2019). The domestic activities have been scheduled with the coefficients reported in the standard, providing the daily profiles related to the variable presence of people inside the building and the operation of lights and appliances. The daily profile of the total internal gains, including occupants, appliances and lights, has been reported in Figure 3 for each thermal zone. These values were used as inputs for the simulations.

Seven configurations of the system have been considered combining the biomass stove and the traditional heating system:

- GBR - gas boiler system with radiators as terminal units

- PS - pellet stove

- DPS - pellet stove with air ducting system

- WS - wood-log stove

- GBR-PS - gas boiler and radiators with a pellet stove

- GBR-DPS - gas boiler and radiators with a pellet stove with air ducting system

- GBR-WS - gas boiler and radiators with a wood-log stove

The DHW energy analysis was not covered in this paper since it does not affect the operation of the considered biomass appliances.

\subsection{Model of the boiler and radiators system}

The conventional heating system consists of a condensing gas boiler used for space heating and DHW production. The water heated in the boiler is delivered to a system of radiators, placed in the heated thermal zone, i.e. Z-1, Z-2, Z-4 and Z-5. The access corridor and the staircase (Z-3) are not provided with terminal units. For radiator sizing, the water temperature difference between the supply and the return is set to $10^{\circ} \mathrm{C}$.

The building envelope model (Type 56) was linked to the space heating distribution system in the Simulation
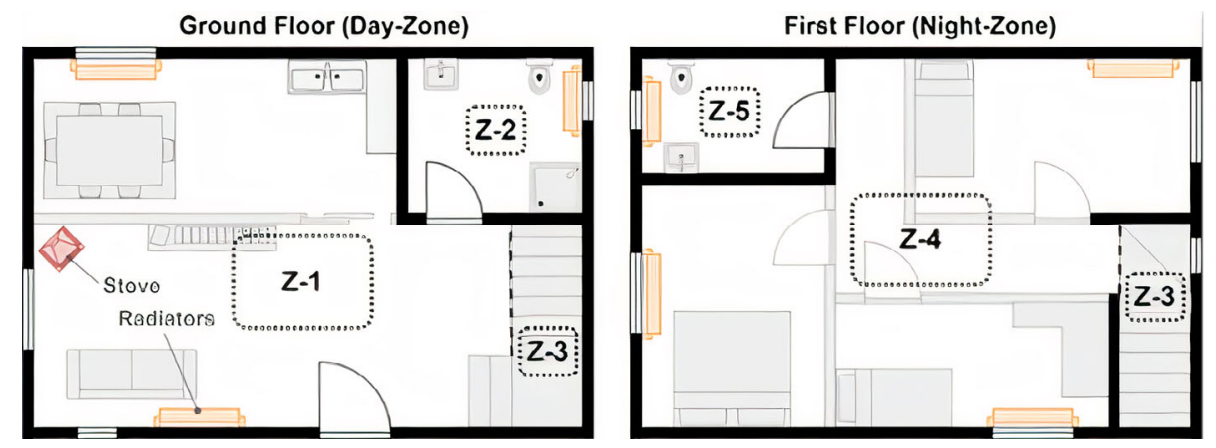

\begin{tabular}{|l|l|}
\hline Z-1 & Living room and kitchen \\
\hline Z-2 & Bathroom (ground floor) \\
\hline Z-3 & Staircase \\
\hline Z-4 & Bedrooms \\
\hline Z-5 & Bathroom (1" floor) \\
\hline
\end{tabular}

Fig. 2 Zoning of the single-family house archetype

Table 1 Geometry and thermal properties of the single-family house

\begin{tabular}{c|c|c|c|c}
\hline \multirow{2}{*}{ Geometry } & Net surface & Net volume & Opaque surface & Glazed area \\
\cline { 2 - 5 } & $134 \mathrm{~m}^{2}$ & $360 \mathrm{~m}^{3}$ & $256 \mathrm{~m}^{2}$ & $20 \mathrm{~m}^{2}$ \\
\hline \multirow{2}{*}{ Envelope } & Vertical walls & Basement & Roof & Windows \\
\cline { 2 - 5 } & $0.41 \mathrm{~W} /\left(\mathrm{m}^{2} \mathrm{~K}\right)$ & $0.40 \mathrm{~W} /\left(\mathrm{m}^{2} \mathrm{~K}\right)$ & $0.39 \mathrm{~W} /\left(\mathrm{m}^{2} \mathrm{~K}\right)$ & $2.30 \mathrm{~W} /\left(\mathrm{m}^{2} \mathrm{~K}\right)$ \\
\hline
\end{tabular}




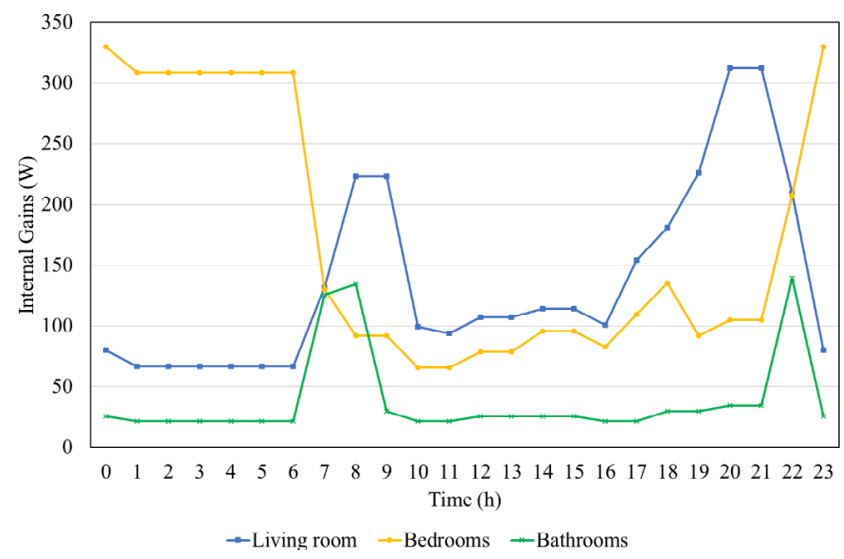

Fig. 3 Daily profile of internal gains (occupants, appliances, lights) for each thermal zone

Studio workspace of TRNSYS, where the mathematical models of the different components of the energy plant can be easily interconnected. In particular, Type 751, from the TESS library of TRNSYS (TESS 2012), was used to simulate the boiler, with a supply temperature of $75{ }^{\circ} \mathrm{C}$ for water heating. The boiler's efficiency in design conditions is $97.4 \%$ and varies depending on the partial load operation of the condensing boiler. The control strategy regulates the hydronic system, including an $80 \mathrm{~W}$ single-speed pump. Manifolds (Types 647 and 649) deliver each radiator the rated water flow rate and mix the return flows. A qualitative model scheme is shown in Figure 4.

As already mentioned, radiators were modelled using Type 1231. The sizing of each radiator was done considering the heating demand of the corresponding thermal zone. Catalogue data for 3-columns steel radiators were employed for setting the parameters used for radiators' models. They were assumed to be 0.75 metres high, with the $n$-exponent equal to 1.32 and a variable number of columns, depending on the required heating capacity. The heat released to the

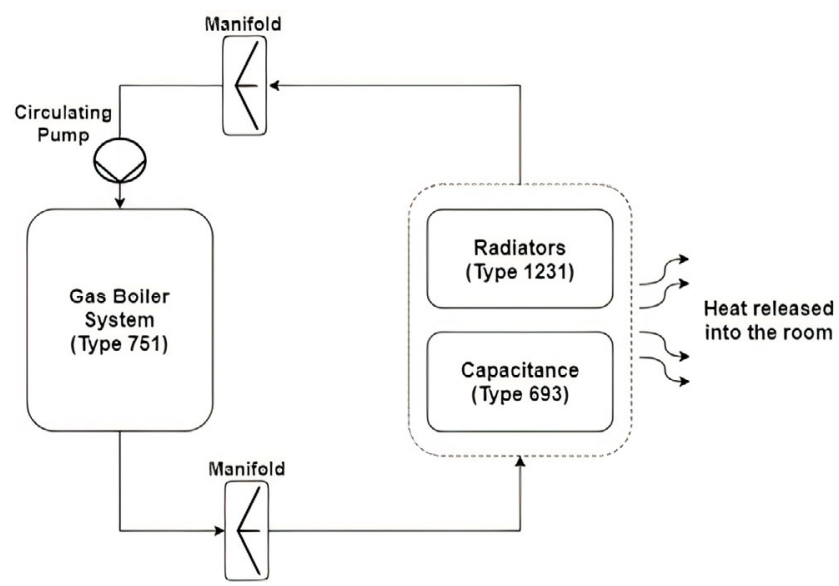

Fig. 4 Scheme of the model for the gas-boiler and radiator system implemented in TRNSYS ambient by each radiator has been modulated using a lumped capacitance model (Type 963, TESS library) to consider the transient effects during the start-up and shut-down phases of the boiler. Therefore, the thermal energy received as input is gradually released to the surrounding ambient according to radiators' thermal inertia, which considers the mass of the metal frame and the water contained within the hydronic circuit. The heat released by the capacitance enters the building as an internal gain, partly convective (70\%) and partly radiative (30\%), according to Risberg et al. (2016). The radiation and convection heat transfer ratio has been considered constant with the radiator's surface temperature variations (Xu et al. 2008).

\subsection{Stove model}

The stove model proposed in this work consists of two parts: the stove on-off and power modulation logic and the physical model of the device. The control system output, which will be described in detail in Section 2.5, is a dimensionless coefficient gamma $(\gamma)$, used to modulate the thermal power of the stove, according to Eq. (1):

$P_{\text {rel }}=P_{\mathrm{n}} \cdot \gamma$

where $P_{\text {rel }}$ is the heat flux released to the environment where the stove is placed, and $P_{\mathrm{n}}$ is the rated power of the stove.

Part of the thermal energy is released to the building with hot air intake through an air blower modelled using Type 139 (Jenkins and Jackson 2010). Air blowers are compact devices that usually operate at fixed speed by forcing the room air circulation through the shell of the firebox or a stainless-steel heat exchanger, as shown in Figure 5. In pellet stoves, air circulation can be limited to the room where the stove is located (PS and GBR-PS) or ducted to other dwelling areas. In DPS and GBR-DPS, the air ducting solution has been implemented using Type 607 and has the double positive effect of avoiding overheating in the living room and increasing the bedrooms' air temperatures. Concerning the air blower operation, a constant airflow rate was set to $75 \mathrm{~m}^{3} / \mathrm{h}$ (Cablé et al. 2019), and a limited airflow temperature was fixed at $50^{\circ} \mathrm{C}$. Thus, the efficiency of the air blower is included in the calculation of the overall efficiency of the stove. In modelling the stove's behaviour during the start-up and shut-down phases (Persson et al. 2009), the convective air blower is switched on and off 12 minutes after the start and the stop signal.

The remaining share of thermal energy is released by the casing of the stove, implemented in the dynamic model using a lumped capacitance model (Type 963). Therefore, the stove is modelled as a box with an external area $A_{\mathrm{s}}$ of 


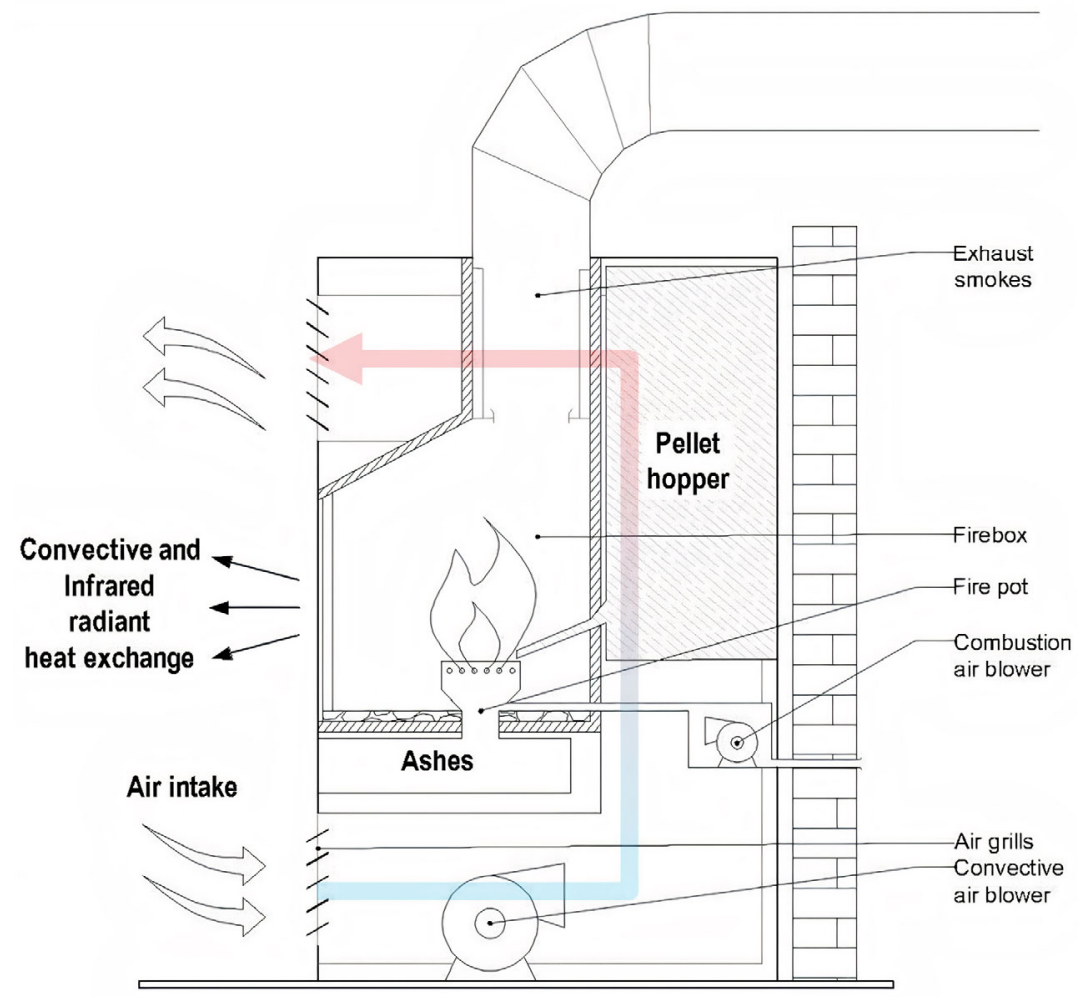

Fig. 5 Layout of a generic pellet stove

$2 \mathrm{~m}^{2}$, according to many products datasheet available on the market (Georges et al. 2014). The lumped capacitance model requires the inertial mass of the body as input, which is described by the parameter $C_{\mathrm{s}}$ (thermal capacitance) and assumes the stove composition and the temperature as spatially uniform. Consequently, the heat release $\left(Q_{\text {rel }}\right.$ in Eq. (2)) depends on the heat pulse generated in the combustion chamber (firebox), the average temperature of the massive stove $T_{\mathrm{s}}$ and the temperature of the air-node $T_{\mathrm{a}}$ (Bergman and Lavine 2017):

$Q_{\text {rel }}=h_{\mathrm{s}} A_{\mathrm{s}} \int_{0}^{t}\left(T_{\mathrm{s}}(t)-T_{\mathrm{a}}\right) \exp \left(-\frac{h_{\mathrm{s}} A_{\mathrm{s}} t}{C_{\mathrm{s}}}\right) \mathrm{d} t$

where $h_{\mathrm{s}}$ is the overall heat transfer coefficient and $t$ is the time. Both for the heating and cooling phase of the stove casing, the time constant $\tau$ can be defined as follows:

$\tau=\frac{C_{\mathrm{s}}}{h_{\mathrm{s}} A_{\mathrm{s}}}$

In this case, the maximum temperature reached by the casing during the peak loads is assumed to be about $200{ }^{\circ} \mathrm{C}$ (Georges et al. 2014). The heat flow is released from the stove to the room by natural convection and longwave radiation. The output power is applied as an internal gain inside the building using the star network approach, described in detail in Seem (1987) and Klein et al. (2014). Since the stove is located in the day-zone, the convective load is released directly into the air-node. The convective and radiative loads are $40 \%$ and $60 \%$ of the output power released, respectively, according to Georges et al. (2014), Kristjansson et al. (2016) and Cablé et al. (2019).

In the presented model, the dynamics of the combustion processes during a cycle length are not treated in detail; however, as in Georges and Novakovic (2012), the combustion is considered instantaneous and managed only by the PID control. This approach has several advantages:

- A detailed description of the stove casing is not required. The model only requires the values for the emitting surfaces and the capacitance of the stove.

- The heat transfer to the room does not occur instantaneously due to the thermal inertia of the stove; therefore, the dynamics involved in the initial and final phases of the combustion process are negligible in terms of energy consumption.

- The fuel consumption can be evaluated through the combustion power and the device's efficiency.

The stove efficiency $(\eta)$ was computed according to European Standards EN 14785 (European Committee for Standardization 2006) for the pellet stove and EN 16510 (European Committee for Standardization 2018) for the wood stove. It defines the overall efficiency considering three losses components: thermal losses in flue gas, chemical losses in flue gas, heat losses due to combustible constituents in 
the residue passing through the grate. According to these Standards, the fuel power $\left(P_{\mathrm{f}}\right)$ was evaluated through Eq. (4):

$P_{\mathrm{f}}=\frac{P_{\text {rel }}}{\eta}$

In Figure 5, the stove system is represented with its main components. As already mentioned, not all the elements are modelled in detail, such as the combustion air blower, which is included in Figure 5 to highlight the different paths of combustion and supply air.

In the present work, a nominal thermal power equal to $10 \mathrm{~kW}$ has been set for both pellet and wood log stoves, as this size represents the most widespread single heating biomass devices in the market. Furthermore, for both cases, the same capacitance $C_{s}(75 \mathrm{~kJ} / \mathrm{K})$ was adopted: this choice is based on the results of previous studies (Georges et al. 2014; Skreiberg and Georges 2018), where similar values are reported as typical for cast iron stoves weighing about $160 \mathrm{~kg}$. For the assessment of the average wood fuel consumption, the efficiency has been set equal to $82.4 \%$ and $72.8 \%$ for pellet and wood log stoves, respectively. The combustion performances are representative of the existing stock in the Italian Po Valley and are based on the age of the appliances and their distribution over the territory, as reported in the survey (Patti et al. 2020). In this contest, the assumed $\mathrm{LHV}_{\mathrm{s}}$ are $17.3 \mathrm{MJ} / \mathrm{kg}$ for pellets and $13.1 \mathrm{MJ} / \mathrm{kg}$ for wood logs, whereas $38.1 \mathrm{MJ} / \mathrm{Sm}^{3}$ is $\mathrm{LHV}_{\mathrm{g}}$ considered for natural gas.

\subsection{Natural ventilation and infiltration model}

In the present study, the residential building was considered naturally ventilated: infiltrations and windows opening provide fresh outdoor air circulating throughout the building and expelled without mechanical equipment. The choice of not including mechanical ventilation systems reflects the low diffusion of these systems in the Po Valley.

The natural ventilation model was implemented using a combination of TRNSYS and CONTAM software. The use of CONTAM to analyse the air mass movement inside the building allows the evaluation of air infiltrations through windows and doors and air couplings between thermal zones. Furthermore, both TRNSYS and CONTAM consider the real-time temperature profiles in each room and the variations in external climatic conditions, enabling dynamic ventilation analysis inside the building.

These aspects are fundamental in high-temperature emitters: the stove releases the whole thermal energy to the surrounding ambient (usually in the living room), increasing the temperature in the installation room while others remain colder. Consequently, users keep generally internal doors open to avoid overheating and, in the meantime, promote heat distribution to other rooms. At this point, a dynamic analysis is essential because of the driving force of the air mass movement, which differs from air couplings to infiltrations: in the first case, the driving force is the density difference between air masses, generated by temperature gradients; in the second case, infiltrations are partly influenced by buoyancy, but also by the wind effect. In both cases, a pressure difference is generated, leading to a flow rate whose value depends on the geometrical characteristics of the openings (Heiselberg 2006).

The same zoning used in TRNSYS was applied; the living room (Z-1) and the bedrooms (Z-4) were modelled as different zones, both linked to the stairwell (Z-3) through an internal door. Once the spaces were defined, openings were designed using a "Two-way flow" model, with a discharge coefficient of 0.61 and flow exponent of $0.5(\mathrm{Ng}$ et al. 2013; Heiselberg 2006). Relative elevation and height were assumed from real openings. The evaluation of the opening area was made in a different way for doors and windows. Internal doors were supposed to be completely open, except in cases comparing open and closed internal doors $(\mathrm{GBR}(\mathrm{c}), \mathrm{PS}(\mathrm{c}))$; in this case, the effective door opening was used as the opening area $\left(2.4 \mathrm{~m}^{2}\right.$ was assumed for internal doors). Concerning the windows opening surface, the same average infiltration value was maintained for all the analysed cases: a value of $0.2 \mathrm{~h}^{-1}$ was set, considering both infiltrations and air changes due to windows opening.

A daily schedule has been set considering a reduction factor for infiltrations between 22:00 and 7:00. The evaluation of the pressure coefficient was made through the model of Swami and Chandra for low-rise buildings (Cóstola et al. 2009; Swami and Chandra 1988).

The software CONTAM was adopted in this work for the following implications:

- The use of defined windows settings allowed the possibility of comparing two different cases, which are the opening and the closing of internal doors.

- Using CONTAM instead of a predefined infiltration value made it possible to dynamically evaluate the heat transfer associated with air movements among different thermal zones of a building. This aspect could be negligible with distributed emitters, but it is fundamental when a single high-temperature heating device is placed in one room.

\subsection{Control strategies}

According to Italian standards, the simulations were performed considering the heating season in the Po Valley starting on October 15th and closing on April 15th. In addition, daily schedules were used to define the operation of the devices at different daytimes. 
The boiler control strategy is defined using two thermostats placed within day and night-zones to maintain the setpoint temperatures. When the gas boiler system is switched on, the day zone temperature is set to $21^{\circ} \mathrm{C}$ at 6:00-9:00, 12:00-14:00 and 16:00-22:00, while it has been set to $18{ }^{\circ} \mathrm{C}$ otherwise; for the night zone, the temperature has been set to a constant value of $18^{\circ} \mathrm{C}$. In order to reduce the frequency of boiler on/off cycles, a tolerance of $\pm 1{ }^{\circ} \mathrm{C}$ is given for both thermostats.

As for the biomass burners, the daily operation time is $11 \mathrm{~h}$ for the pellet stove, and $10 \mathrm{~h}$ for the wood-burning stove, according to the survey published by the Regional Agency for Environmental Protection (ARPAV 2015). Therefore, the considered operating intervals are 6:00-9:00, 12:00-14:00 and 16:00-22:00 for the pellet stove, and 6:00-11:00 and 17:00-22:00 for the wood log stove. In the latter case, it is reasonable to count a double firing, one in the morning and one in the afternoon, as this is not usually managed autonomously as in pellet stoves. The stoves are kept working and regulated during these time frames based on the ambient thermostat through power modulation in the combustion chamber.

Once the stove starts up, the heat is released into the room for several hours due to its massive inertia, even after it has been turned off. Therefore, there may be excessive room overheating on days characterised by wide temperature variations, particularly in the central hours of the day. To overcome this problem, it is assumed that above a threshold value of the outside air temperature $\left(T^{*}\right.$, set at $12{ }^{\circ} \mathrm{C}$ ), the stove does not start up and the required space heating is provided using an auxiliary heater (e.g., gas boiler, electrical heater).

The power modulation of the stove is carried out via a Proportional Integral Derivative (PID) controller implemented in the dynamic model with Type 23. The stove power response is driven by $\gamma$, a dimensionless coefficient varying between the ratio $P_{\min } / P_{\mathrm{n}}$ and 1 according to the deviation detected between the actual temperature of the thermal zone and the setpoint temperature. The difference between these two temperature values, at each timestep, is expanded through the proportional, integral and derivative effects, obtaining the $\gamma$ coefficient. Following (Georges et al. 2014; Cablé et al. 2019) and the technical data sheets of several manufacturers, when the pellet stove is switched on, $P_{\min }$ is limited down to $30 \%$ of the rated power ( $\gamma$ operates between 0.3 and 1). Differently, the wood stove operates in a batch process and, therefore, less flexibility is allowed due to the manual filling, which is also conditioned by the size of the wooden logs. For the latter device, $P_{\min }$ is assumed to be $50 \%$ of the rated power ( $\gamma$ operates between 0.5 and 1 ). Figure 6 shows the operation of the stove during a typical winter day. It can be seen that the heat flux generated by

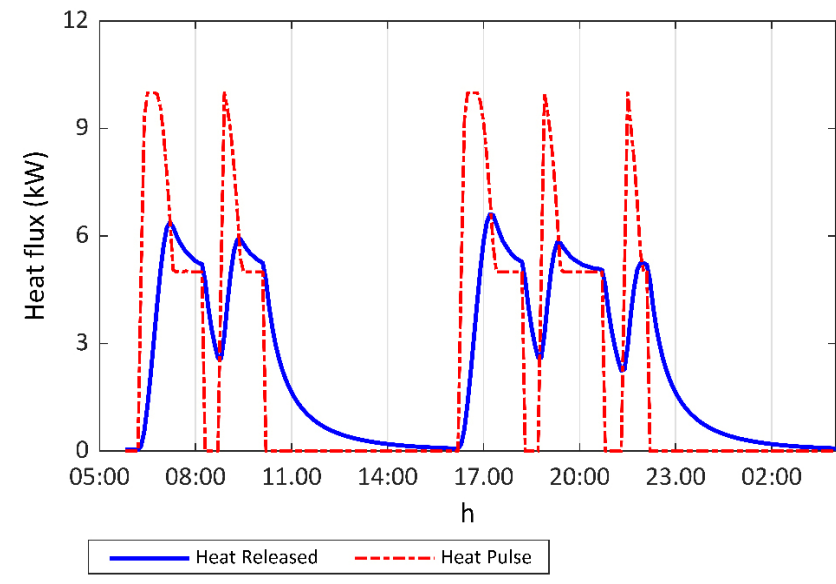

Fig. 6 Heat pulse applied to the wood stove capacitance model and the heat released to the environment through the stove casing

the burning of the biomass is stored in the stove case, which presents certain inertia and that slowly releases it to the ambient, depending on its thermal capacitance.

In the case of wood stoves, the inner temperature control is supposed to be done manually by the user; hence the maximum temperature that can be reached before the turning off is set at $26^{\circ} \mathrm{C}$. Furthermore, in agreement with Georges and Novakovic (2012) and Oehler et al. (2016), a minimum cycle time has been set for both devices. For the pellet stove, the minimum cycle time has been set at $0.6 \mathrm{~h}$ and includes both the time required for fuel preparation (about $10 \mathrm{~min}$ ) and to reach the rated power. On the other hand, the wood-burning stove is conditioned by batch operation, and the minimum cycle duration has been set to $1.5 \mathrm{~h}$. In Figure 7, two flow charts show both the boiler and the stove controls.

\section{Methods}

\subsection{Energy analysis}

In this section, the methodology applied for energy calculations is presented. The energy analysis has been carried out considering the ideal space heating needs $\left(Q_{\mathrm{nd}}\right)$, the final energy demand $\left(Q_{\mathrm{d}}\right)$ and the primary energy consumption $\left(E_{\mathrm{P}}\right)$. The different energy outputs were obtained through dynamic simulations using TRNSYS (Klein et al 2014). In particular, the calculation of $Q_{n d}$ is carried out through the thermal balance of the building, considering the presence of an ideal convective heating system maintaining the setpoint temperatures (see Section 2.5). The implementation of the heating system leads to the definition of $Q_{\mathrm{d}}$, which is calculated from the energy input of generators in the real system model. Once the final energy is obtained, the conversion to $E_{\mathrm{P}}$ is made by the application of primary energy factors (PEFs). 

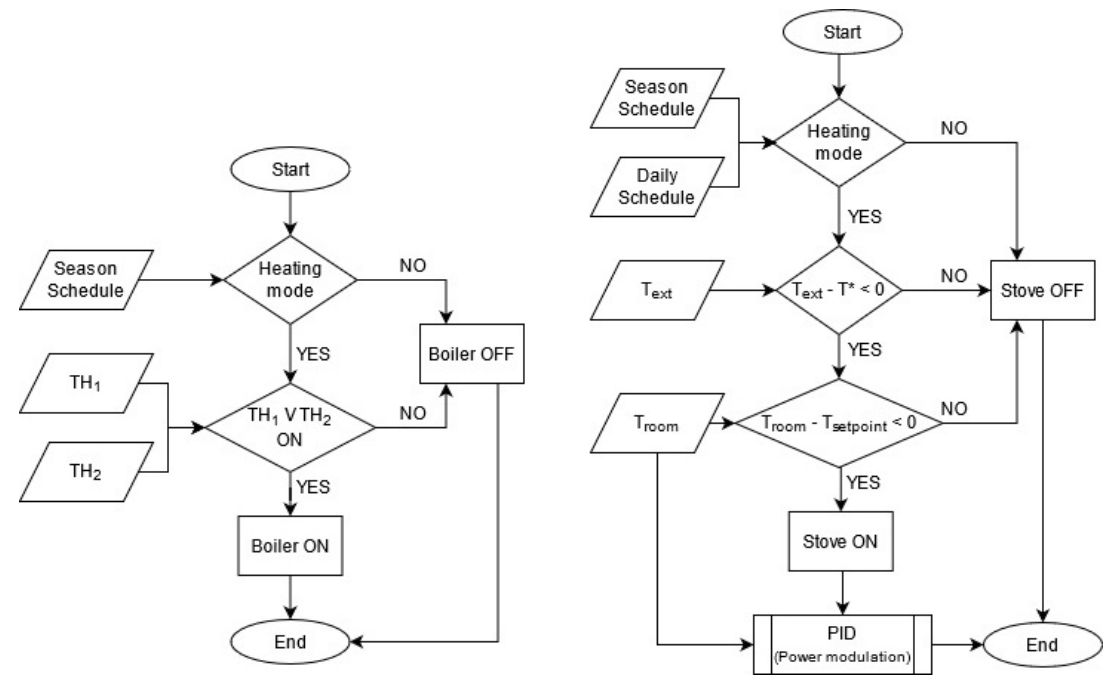

Fig. 7 Block diagrams of the boiler control (left) and the stove control (right)

With the implementation of the system models in the simulations, it was noticed that when the biomass stove is the unique heating system in the house (PS, DPS and WS), it is not sufficient to maintain uniform indoor temperatures. It follows that the energy consumption for heating the first floor is lower than cases with gas boiler and radiators alone (GBR) and combined with biomass stove (GBR-PS, GBR-DPS and GBR-WS). Hence, the amount of energy required to balance the space heating needs of the night zone is indicated as the residual need $\left(Q_{\mathrm{res}}\right)$, as shown in the diagram of Figure 8. For carrying out the final and primary energy demand analysis, the residual need is assumed to be covered by an electrical heater and added to the final energy consumption of the pellet stove in PS and DPS, and the wood-log stove in WS.

In the diagram of Figure 8, the term "losses" refers to the losses considered in the overall efficiency definition for biomass devices (see Section 2.3), while it stands for generation, distribution and control losses when speaking

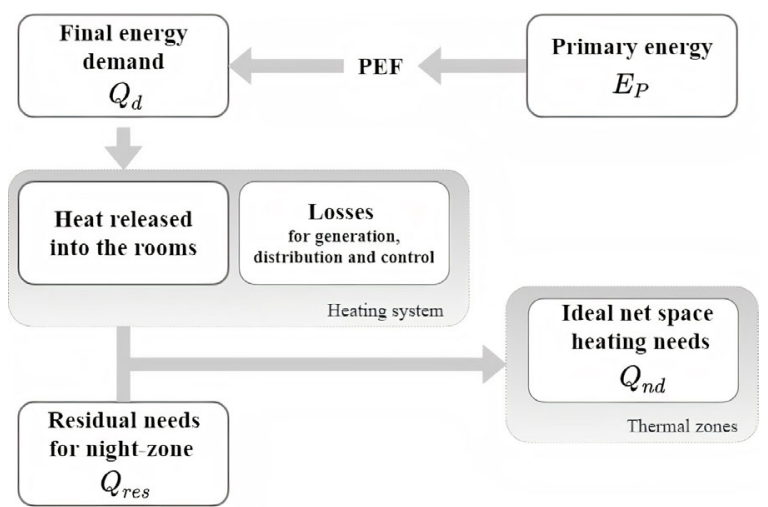

Fig. 8 Diagram of the energy flow pattern of the building's heating system and thermal zones. The diagram shows the additional energy share $\left(Q_{\text {res }}\right)$ needed for ideal net space heating need about the gas boiler system, according to the European Standard EN 15316 (European Committee for Standardization 2017).

In PS, DPS and WS, the residual energy need $\left(Q_{\mathrm{res}}\right)$ related to the zones of the building without terminals (i.e. the night zone) has been calculated as the annual difference between the net energy need for space heating $\left(Q_{n d}\right)$ and the heat transferred by air ducting (if any), internal air couplings and the heat transmitted via conduction through the slab dividing the ground and the first floor. For this purpose, a coverage factor (CF) has been introduced to check the effect of the biomass device on the other zones defined as:

$\mathrm{CF}=1-\left(\frac{Q_{\mathrm{res}}}{Q_{\mathrm{nd}}^{\prime}}\right)$

where $Q_{\text {nd }}^{\prime}$ is the energy need of the night-zone.

Concerning the primary energy analysis, the thermal energy of the heating systems has been considered (depending on the different energy carriers) as well as the electric energy for auxiliaries according to the Italian standard UNI 11300-4 (Italian Organisation for Standardisation 2012), i.e. the circulation pump and air blowers. A comparison between the Italian and European definitions for the primary energy factors has been carried out to provide results related to the local conditions of the case study and show the potential implications on average at the European level. The PEFs values are reported in Table 2 in terms of renewable and non-renewable share. Besides the different assessment of gas and electricity factors, the main difference is represented by the PEF of biomasses. In Italian legislation, they are not categorised by fuel type. At European level, however, the standard EN 15603:2008 (European Committee for Standardization 2008) provides the PEF for wood, 
Table 2 Primary energy factors (PEFs)

\begin{tabular}{lcccc}
\hline & PEF & Non-renewable (nren) & Renewable (ren) & Total \\
\hline & Natural gas & 1.36 & - & 1.36 \\
European standard (EN 15603:2008) & (European & Wood pellet & 0.11 & 1.19 \\
Committee for Standardization 2008) & Wood log & 0.09 & 1.00 & 1.30 \\
& Electric mix & 3.14 & 0.17 & - \\
\hline & Natural gas & 1.05 & 0.8 & 1.09 \\
Italian Standard (UNI/TS 1300-4) (Italian Organisation & Biomass (solid) & 0.20 & 1.05 \\
for Standardisation 2012) & Electric mix & 1.95 & 0.47 \\
\hline
\end{tabular}

*Sourced by IINAS (Fritsche and Greß 2015)

while for pellets, it is possible to refer to the values of the International Institute for Sustainability Analysis and Strategy (IINAS) (Fritsche and Greß 2015). Hence, the European PEFs of wood log and wood pellet have been considered different, while the same value has been adopted for Italy.

\subsection{Economic Analysis}

The annual consumption presented in this paper was also compared from an economic point of view to provide a comprehensive analysis of the different systems. Such analysis is reasonable as this work aims to compare an ordinary and average use of the biomass and gas boiler systems in a typical house archetype with regular energy performance, such as most houses where biomass devices are currently installed in the Italian scenario (Patti et al. 2020). Moreover, the main output of this work is not a comparison of the convenience of different types of systems but a study of energy consumption. For this reason, it was thought that a costs analysis of the energy component, neglecting the other aspects (installation, maintenance), was the most effective approach to complete the work, enriching the results with an economic aspect.

The annual cost for heating was estimated by multiplying the final fuel consumption resulting from simulations and the Italian gross energy price (including VAT) reported by Eurostat for natural gas $(0.09 € / \mathrm{kWh})$ (https://www.arera.it) and Eurostat for electricity $(0.21 € / \mathrm{kWh})$ (https:// ec.europa.eu/eurostat), pellets $(0.31 € / \mathrm{kg}$ ) (Gauthier et al. $2020)$ and firewood $(0.15 € / \mathrm{kg})$ (https://www.aielenergia.it).

\section{Results and discussion}

In this chapter, the simulation outputs are shown and discussed. First, the results concerning the operative temperature (Section 4.1) and the infiltration and air-coupling analysis (Section 4.2) are reported; despite the simplified model, the results shown in these sections highlight some significant aspects. The proposed model does not aim at a detailed definition of the motion field; however, the multi-zone modelling allows some considerations on energy transport through air masses to be made. Then, in Section 4.3 , the energy analysis is presented, which is the main output of this work. Finally, in Section 4.4, the results of the economic analysis are shown.

\subsection{Operative temperature}

The mean operative temperature of the zonal air-node as well as the 5-th percentile $\left(T_{\mathrm{op}, 5 \%}\right)$ and 95-th percentile $\left(T_{\mathrm{op}, 95 \%}\right)$ were used to compare the different cases. In this analysis, it is more interesting to focus on zones Z-1 and Z-4 since they represent the behaviour of both day- and night-zones.

For the configuration with gas boiler and radiators, the closing $(\mathrm{GBR}(\mathrm{c}))$ or opening (GBR) of the staircase doors has a negligible influence on the mean temperature of the living room and bedrooms because radiators can maintain the desired level of thermal comfort in the respective areas (i.e. $18-20^{\circ} \mathrm{C}$ ), as shown in Figure 9. However, in the case with the pellet stove and closed doors (PS(c)), the absence of airflow through the staircase leads to a decrease in the mean temperature, which drops to $16.1^{\circ} \mathrm{C}$ in the bedrooms (Figure 9(b)), with a temperature reduction of about $1.8^{\circ} \mathrm{C}$ compared to the case with open doors (PS). As a result, the mean temperatures in the living room are generally higher in PS than GBR and GBR(c) (Figure 9 (a)).

When the biomass stove is installed in the living room, simulations are performed considering open doors to simulate more realistic operating conditions. In Figure 10, the operative temperatures in the different cases are compared for the day-zone (Figure 10(a)) and the nightzone (Figure 10(b)). The presence of distributed emitters takes to a more uniform temperature in different thermal zones: in GBR case, the average operative temperature difference between day and night zone is $0.4^{\circ} \mathrm{C}$; in all the other cases, the difference is wider. Another relevant aspect concerns the wood-burning stove, which presents a different dynamic influenced by low modulation capacity and greater minimum cycle length (batch logs combustion). In 

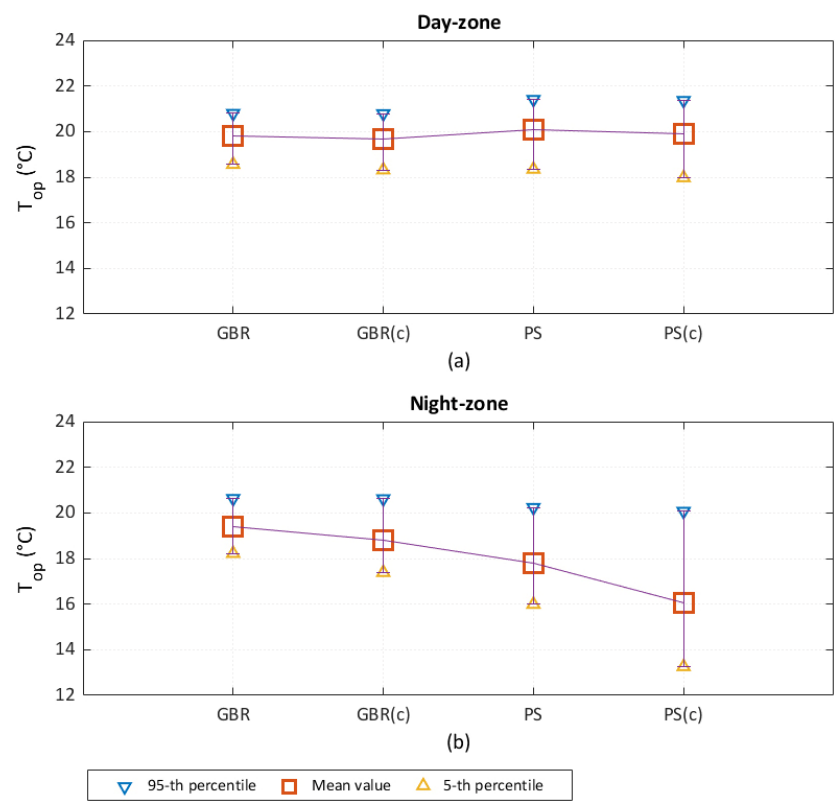

Fig. 9 Operating temperatures in GBR and PS configurations. The graphs compare the opening (GBR and PS) and closing (GBR(c) and PS(c)) of the staircase doors for both day (a) and night (b) zones
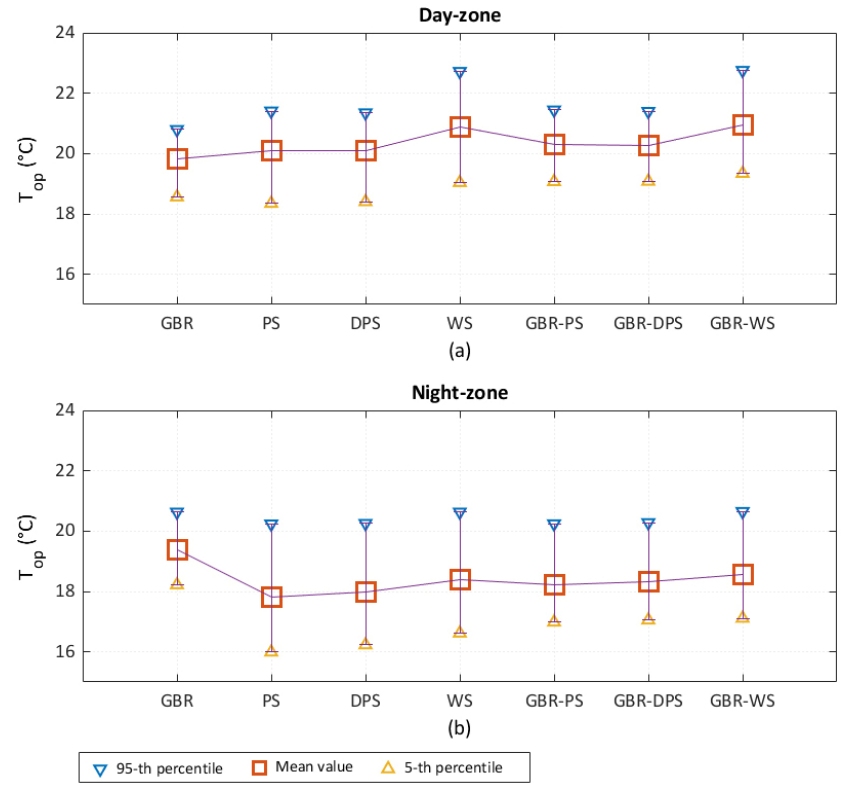

Fig. 10 Operating temperature comparison for the various case studies, both for the day (a) and night (b) zones

Figure 10, it can be observed that temperatures in the living room also reach $22.8^{\circ} \mathrm{C}$ for both WS and GBR-WS. In GBR-PS, GBR-DPS and GBGR-WS combined system operation, the night-zone's operating temperature range is almost similar.

\subsection{Infiltrations and air-couplings}

Comparing GBR and PS configurations, significant differences were found regarding infiltrations (INF); thus, it is useful to divide the results into two clusters, referring to the cases where open (or closed) internal doors are considered. In general, if all the internal doors are open, the external air entering the lower part of the building (ground floor) is heated and moves to the upper floor through the staircase, exiting via the first-floor openings. Figure 11 shows that most infiltrations enter the living room; furthermore, when the living room and bedrooms are not communicating ("Closed" case), the incoming airflow is reduced, on average, with an increase in infiltrations only in the night-zone. As shown in Figure 11, the mean value of infiltration changes from $0.19 \mathrm{~h}^{-1}$ to $0.13 \mathrm{~h}^{-1}$, while in percentile terms, from $0.03 \mathrm{~h}^{-1}$ to $0.06 \mathrm{~h}^{-1}$ for $\mathrm{INF}_{5 \%}$ and from $0.43 \mathrm{~h}^{-1}$ to $0.4 \mathrm{~h}^{-1}$ for $\mathrm{INF}_{95 \%}$. These results are in good agreement with those found in the case studies carried out for other countries such as China (Lamberg et al. 2017), France (Tol 2020), Denmark (Xu et al. 2008) and the UK (Oehler et al. 2016).

The behaviour of air couplings inside the building regards the flow through the staircase. Figure 12 shows that air couplings flow rates are lower when the heating system involves lower temperature differences between zones. Therefore, since in GBR the zoning temperature effect is reduced due to the system terminals distributed throughout the building, IAC events are limited. In all other cases, the presence of the biomass system leads to higher temperatures in the thermal zone where the stove is placed. When this effect is highlighted, as it happens for PS and WS, air tends to move from the day-zone towards the upper night-zone and consequently, IAC $_{\text {mean }}$ and IAC $_{95 \%}$ increase. Air ducting systems (DPS and GBR-DPS) lead to slightly lower IACs than simple stove systems. As shown in Section 4.1, the temperature gradients between the thermal zones can influence the airflows; in particular, the internal gain of the stove affects the IACs, as reflected in the difference between

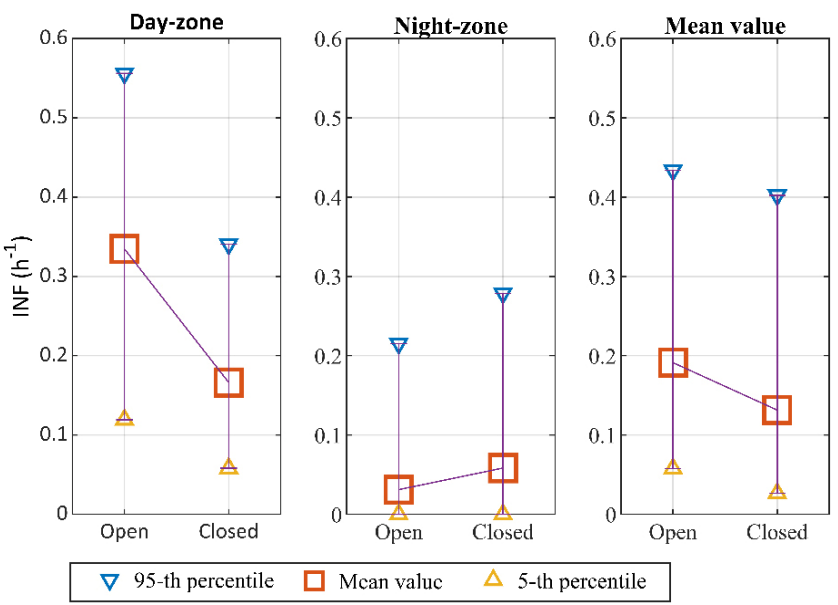

Fig. 11 Infiltration rate for the day zone, night zone and its mean value by comparing the opening and closing of the staircase doors 

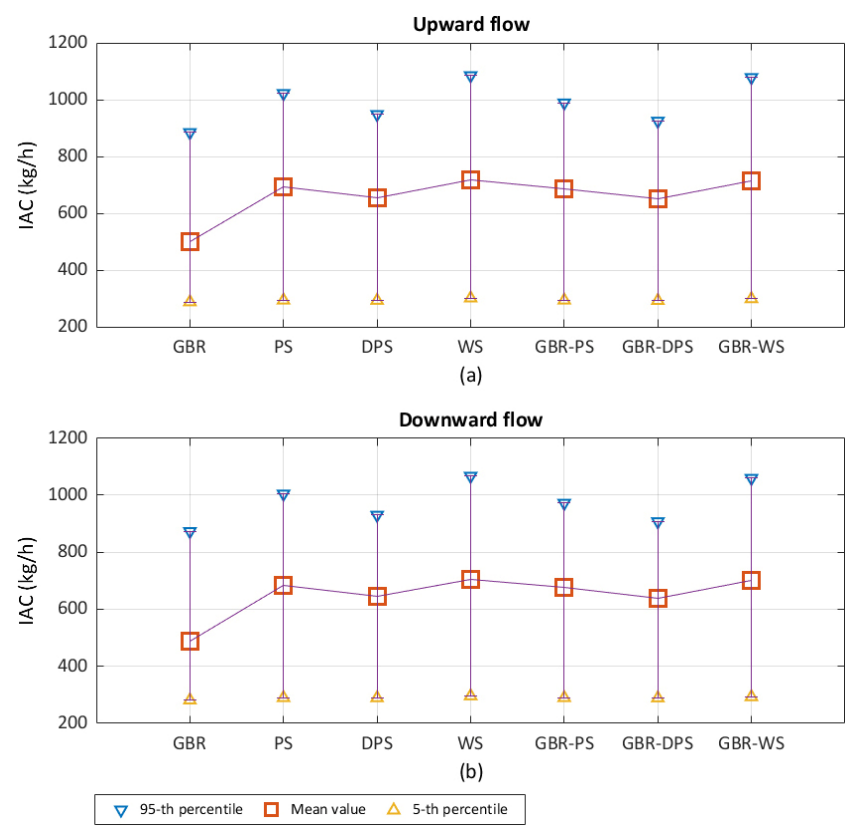

Fig. 12 Internal air coupling (IAC) comparison for the various case studies

for both day and night zones in GBR and PS configurations GBR and all other configurations. Also, the employment of air ducts has a relatively small effect on air coupling.

\subsection{Energy analysis results}

The ideal space heating needs were calculated to compare the different cases properly, as they differ only in the heating system. The $Q_{\text {nd }}$ is $35.6 \mathrm{kWh} /\left(\mathrm{m}^{2}\right.$ year $)$ for all the cases.

In Table 3, the residual load $\left(Q_{\text {res }}\right)$ and the coverage factor $(\mathrm{CF})$ are shown, as well as the share of the heat transfer between the ground floor and the first floor in PS, DPS and WS. In DPS configuration, the coverage factor is about $20 \%$ greater than in PS and WS due to air ducts. In all cases, about $5 \%$ of the heat is transferred via conduction through the slab dividing ground and first floor. In Table 3, the air ducting in DPS plays an important role (37\%) in the heat transfer between the ground and the first floor. The IAC is relevant in the heat transfer between the ground floor and the first floor, being 95\% in GBR and DPS and $58 \%$ in PS.

The final energy analysis is shown for each configuration in Figure 13, including the auxiliary systems, which have been considered separately from the electrical heaters. In Table 4, the sharing of the different energy carriers for the case studies is presented. In GBR, the whole building is heated by radiators, resulting in more significant energy expenditure than in PS and DPS, neglecting the contribution of electric heaters. However, comfort conditions decay in the bedrooms in these cases, resulting in lower zone
Table 3 Coverage factor $(\mathrm{CF})$, residual need for space heating $\left(Q_{\mathrm{res}}\right)$ related to the overall net floor area and percentage of the heat exchange mechanism in the different cases

\begin{tabular}{cccccccc}
\hline & $\begin{array}{c}\text { Air ducting } \\
\text { into night } \\
\text { Cases }\end{array}$ & $\begin{array}{c}\text { Qres } \\
{[\mathrm{kWh} /}\end{array}$ & $\mathrm{CF}$ & \multicolumn{3}{c}{$\begin{array}{c}\text { Percentage of sharing of } \\
\text { heat exchange }\end{array}$} \\
\cline { 6 - 8 } & zone & $\mathrm{m}^{2}$ year $\left.)\right]$ & {$[-]$} & Ducting & IAC & Conduction \\
\hline PS & No & 8.6 & 0.39 & $0 \%$ & $94 \%$ & $6 \%$ \\
DPS & Yes & 7.4 & 0.47 & $37 \%$ & $58 \%$ & $5 \%$ \\
WS & No & 9.0 & 0.40 & $0 \%$ & $95 \%$ & $5 \%$ \\
\hline
\end{tabular}

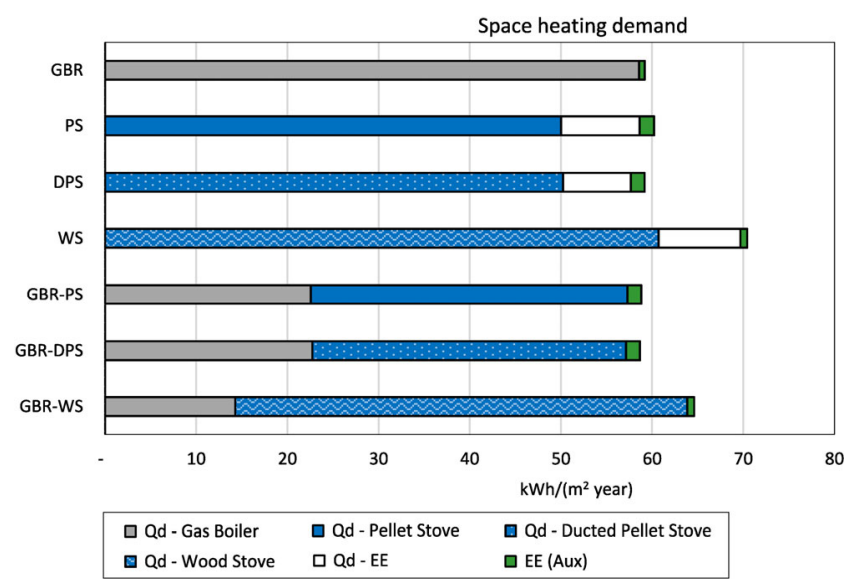

Fig. 13 Final energy consumption of heating systems by fuel type in the various case studies

temperature than in other cases. Therefore, DPS configuration consumes slightly more than the reference GBR case. The energy input solely due to pellet stoves is nearly equal for PS and DPS, about $50 \mathrm{kWh} /\left(\mathrm{m}^{2}\right.$ year). Overall, including the electric heaters (EE), the final energy used in DPS is almost the same as GBR, i.e. $59.2 \mathrm{kWh} /\left(\mathrm{m}^{2}\right.$ year $)$, while PS requires $2 \%$ more energy, $60.2 \mathrm{kWh} /\left(\mathrm{m}^{2}\right.$ year $)$. The difference between PS and DPS can be explained by two combined effects. First, the ducted pellet stove slightly increases the internal temperature in the night-zone compared to PS, as already discussed for the coefficient CF. Secondly, driving more energy in the night-zone increases the operating hours in the day-zone of the pellet stove, thus leading to higher mean power output $(5.6 \mathrm{~kW})$ in DPS than in PS (5.3 kW).

The traditional wood stove alone (WS) provides final energy of about $60.7 \mathrm{kWh} /\left(\mathrm{m}^{2}\right.$ year $)$. Excluding electric heaters, the final energy is $4 \%$ higher compared to GBR. The biomass consumption is $22 \%$ higher than PS and DPS. Considering the electric heaters, the overall consumption is $70 \mathrm{kWh} /\left(\mathrm{m}^{2}\right.$ year $)$, about $20 \%$ higher than GBR, PS, and DPS.

A combined operation of biomass stoves and the standard natural gas heating system (GBR-PS, GBR-DPS and GBR-WS) occurs when the temperature drops below the set-back. In terms of overall consumption, GBR-PS and 
Table 4 Sharing of final energy in different case studies

\begin{tabular}{cccccccc}
\hline & GBR & PS & DPS & WS & GBR-PS & GBR-DPS & GBR-WS \\
\hline Final energy $\left[\mathrm{kWh} /\left(\mathrm{m}^{2}\right.\right.$ year$\left.)\right]$ & 59.2 & 60.2 & 59.2 & 70.4 & 58.8 & 58.7 & 64.6 \\
Gas & $99 \%$ & $0 \%$ & $0 \%$ & $0 \%$ & $38 \%$ & $39 \%$ & $22 \%$ \\
Biomass & $0 \%$ & $83 \%$ & $85 \%$ & $86 \%$ & $59 \%$ & $59 \%$ & $77 \%$ \\
Electrical heater & $0 \%$ & $14 \%$ & $13 \%$ & $13 \%$ & $0 \%$ & $0 \%$ & $0 \%$ \\
Auxiliaries (pumps and fans) & $1 \%$ & $3 \%$ & $3 \%$ & $1 \%$ & $3 \%$ & $3 \%$ & $1 \%$ \\
\hline
\end{tabular}

GBR-DPS configurations are slightly lower than GBR. GBR-WS presents 9\% higher final energy consumption than GBR. When using the electric auxiliary heater (PS and DPS), the final energy consumption for space heating is comparable to a combined pellet stove and gas boiler systems configuration, such as in GBR-PS and GBR-DPS.

In general, the higher energy consumption associated with the use of the wood stove compared to the pellet stove is mainly due to the lower burning efficiency of wood log systems compared to pellet devices and their limited ability to modulate the power output.

The graphs in Figure 14 show the primary energy comparison between the different case studies analysed in this work. It can be noticed that the residual need satisfied with the electric device has a significant impact on the primary energy calculation: PS, DPS and WS configurations
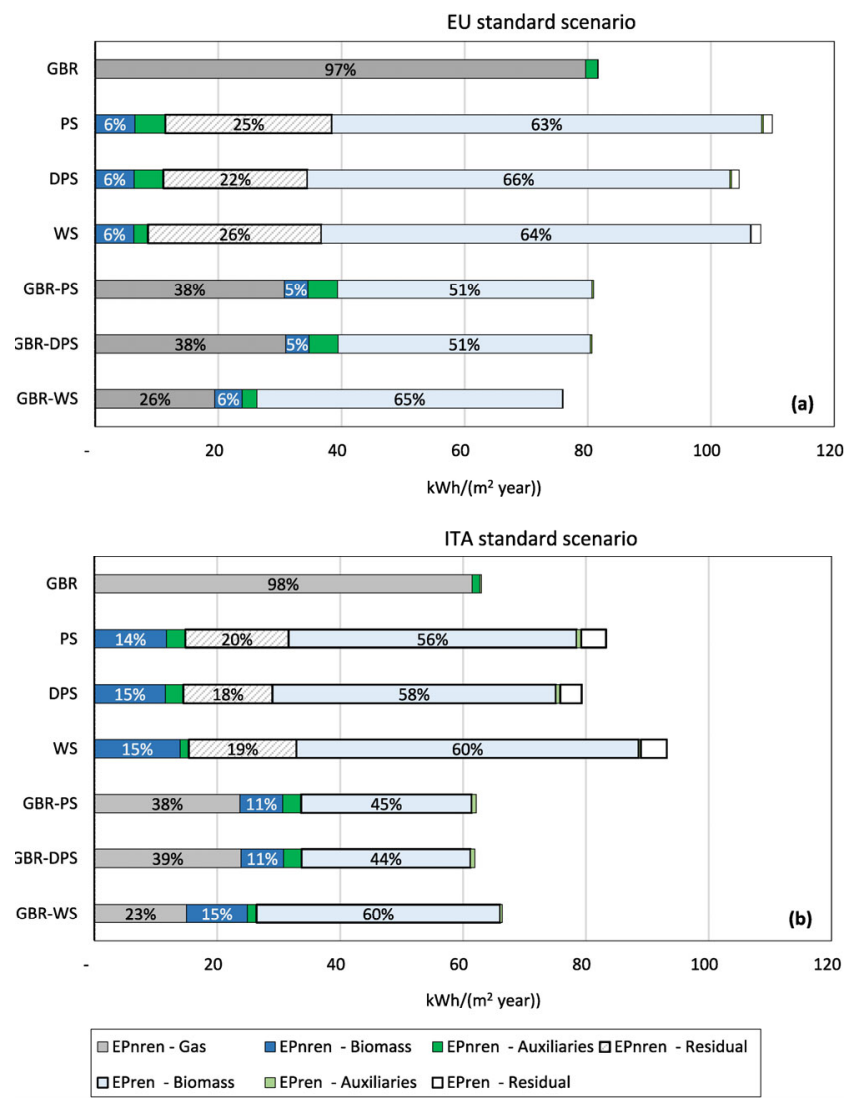

Fig. 14 Results of the primary energy analysis based on European values (a) and Italian values (b) result in a higher overall primary energy use compared to the respective cases where biomass devices are combined with a gas boiler and radiator system. However, GBR, GBR-PS and GBR-DPS present similar relative values of overall primary energy (Table 5), while WS and GBR-WS differ depending on the value of PEF for wood compared to pellet. Therefore, the primary energy evaluation performed with the EU standards is lower in cases with wood-log devices.

Looking at renewable and non-renewable primary energy, GBR is almost entirely non-renewable due to the use of natural gas. In PS, DPS and WS, the $E_{\mathrm{P} \text {,ren }}$ share is between $62 \%$ and $65 \%$ for the Italian context and $65 \%$ and $67 \%$ for the European (see Table 5). In combined systems, the $E_{\mathrm{P}, \text { ren }}$ share is lowered due to the natural gas contribution and it results about to $46 \%$ and $51 \%$ for pellet stove (GBR-PS and GBR-DPS), and about to $60 \%$ and $65 \%$ for wood-log stove (GBR-WS), respectively for the Italian and the European reference used.

Concerning the electric heater device (PS, DPS and WS), the $E_{\mathrm{P} \text {,nren }}$ accounts for about $20 \%$ and $25 \%$, respectively, for the Italian and EU case. Moreover, when the pellet stove is coupled with the radiator system (GBR-PS and GBR-DPS), the $E_{\mathrm{P} \text {,nren }}$ related to natural gas is about $38 \%$ and drops to $25 \%$ in a combined wood stove and gas boiler system (GBR-WS). This difference is due to the prevalent use of the stove caused by the low modulating capacity of wood-log devices. The electricity share related to auxiliary systems of pellet stoves (i.e. fans) is about $6 \%$ and for the wood stove is about $3 \%$ considering both Italian and European PEFs.

\subsection{Economic analysis results}

In this section, the analysis is also extended to the economic aspect of household heating. The annual cost for the GBR system can be estimated at $720 € /$ year, while it results at about $460 € /$ year for PS and DPS and $350 € /$ year for WS. Compared to the GBR reference case, biomass systems reduce the annual cost - by $36 \%$ and $51 \%$ for pellet and wood stove, respectively - but do not provide an optimal heat distribution in the house, as shown in the previous paragraphs. On the other hand, significant savings of 
Table 5 Percentage increase (positive) and decrease (negative) of the overall primary energy and non-renewable primary energy in the different cases compared to the reference GBR configuration, considering European and Italian PEF values

\begin{tabular}{cccccccc}
\hline & & PS & DPS & WS & GBR-PS & GBR-DPS & GBR-WS \\
\hline European & Overall & $35 \%$ & $28 \%$ & $32 \%$ & $-1 \%$ & $-1 \%$ & $-7 \%$ \\
PEF & Non-renewable & $-53 \%$ & $-58 \%$ & $-55 \%$ & $-52 \%$ & $-52 \%$ & $-68 \%$ \\
\hline Italian & Overall & $32 \%$ & $26 \%$ & $48 \%$ & $-1 \%$ & $-2 \%$ & $5 \%$ \\
PEF & Non-renewable & $-50 \%$ & $-54 \%$ & $-48 \%$ & $-46 \%$ & $-46 \%$ & $-58 \%$ \\
\hline
\end{tabular}

$17 \%$ are achieved in case of coupling the GBR-PS system (600 €/year) and in the case of GBR-DPS and GBR-WS system where the saving is about $36 \%$ (460 €/year) due to the lower use of gas compared to the reference case.

\section{Conclusions}

In this work, the behaviour of different heating systems installed in existing residential buildings was compared in terms of final and primary energy consumption, using an integrated TRNSYS and CONTAM dynamic model to partly cover the lack of energy analyses related to the presence of biomass burners in residential buildings. In particular, the operation of a single stove system (pellet or wood) placed in the living room and the combined use of a stove and a standard heating system (radiators and boilers) were analysed for a mild climate. It was found that:

- The opening of internal doors promotes an increase in the air circulation inside the building (estimated between 55\% and $70 \%$ ) when the heating system includes a device located in one room, rather than in the case of distributed terminals; for the case study analysed, simulations showed that $40 \%$ of the energy needs of the night-zone could be covered by the heat provided by the stove through air circulation.

- Biomass stoves are usually oversized for the heating needs of the room in which they are located. This aspect is emphasised in wood-burning stoves, which lead the room to higher air temperatures, due to the lower capacity to modulate the thermal output of these devices; with these systems, the maximum operating temperature obtained in the day-zone is $1.4{ }^{\circ} \mathrm{C}$ higher than with the pellet systems and $2.7^{\circ} \mathrm{C}$ higher than with the radiator systems.

- In terms of final energy, the pellet stove leads to similar results to the gas boiler and radiator system, while the wood stove leads to an increase of $21 \%$ with the electric heater and $9 \%$ with the gas boiler system.

- As far as primary energy is concerned, the use of electric stoves combined with biomass stoves is unfavourable (an increase between 26\% and 48\% was found compared to cases without). On the other hand, the combination of a gas heating system and a wood stove leads to similar overall primary energy consumption, compared to a gas boiler system $( \pm 5 \%)$.
- Although their use does not necessarily imply significant final energy savings, biomass systems allow to increase the share of renewable primary energy considerably; in the analysed case study, the renewable share, which is zero in the absence of biomass installations, increases to values up to $50 \%$ and $65 \%$.

\section{Acknowledgements}

This study was developed from the Action D3 of the LIFE+ PREPAIR Project (https://www.lifeprepair.eu/) which received funding from LIFE Program, under Grant Agreement LIFE 15 IPE IT013. The authors gratefully acknowledge the support of the Regional Agency for Environmental Protection of Veneto (ARPAV), in particular thanks are due to Dr. Silvia Pillon and Dr. Laura Susanetti.

Open Access: This article is licensed under a Creative Commons Attribution 4.0 International License, which permits use, sharing, adaptation, distribution and reproduction in any medium or format, as long as you give appropriate credit to the original author(s) and the source, provide a link to the Creative Commons licence, and indicate if changes were made.

The images or other third party material in this article are included in the article's Creative Commons licence, unless indicated otherwise in a credit line to the material. If material is not included in the article's Creative Commons licence and your intended use is not permitted by statutory regulation or exceeds the permitted use, you will need to obtain permission directly from the copyright holder.

To view a copy of this licence, visit http://creativecommons.org/licenses/by/4.0/

\section{References}

ARPAV (2015). Indagine sul consumo domestico di biomasse legnose in Veneto. Regional Agency for Environmental Protection of Veneto (ARPAV). Available at https://www.arpa.veneto.it/temiambientali/aria/file-e-allegati/Consumi\%20domestici\%20legna\% 20in\%20Veneto_1.0.pdf/view (in Italian)

Bergman T, Lavine A (2017). Fundamental of Heat and Mass Transfer, 8th edn. Hoboken, NJ, USA: John Wiley and Sons, 
Cablé A, Georges L, Peigné P, et al. (2019). Evaluation of a new system combining wood-burning stove, flue gas heat exchanger and mechanical ventilation with heat recovery in highly-insulated houses. Applied Thermal Engineering, 157: 113693.

Cai N, Chow WK (2014). Numerical studies on heat release rate in a room fire burning wood and liquid fuel. Building Simulation, 7: 511-524.

Calderón C, Avagianos I, Jossart J (2020). Report Bioheat. Bioenergy Europe. Available at: https://bioenergyeurope.org/article.html/258.

Carlon E, Verma VK, Schwarz M, et al. (2015). Experimental validation of a thermodynamic boiler model under steady state and dynamic conditions. Applied Energy, 138: 505-516.

Carlon E, Schwarz M, Prada A, et al. (2016). On-site monitoring and dynamic simulation of a low energy house heated by a pellet boiler. Energy and Buildings, 116: 296-306.

Carvalho RL, Jensen OM, Afshari A, et al. (2013). Wood-burning stoves in low-carbon dwellings. Energy and Buildings, 59: 244-251.

Carvalho RL, Jensen OM, Tarelho LAC (2016). Mapping the performance of wood-burning stoves by installations worldwide. Energy and Buildings, 127: 658-679.

Caserini S, Livio S, Giugliano M, et al. (2010). LCA of domestic and centralized biomass combustion: The case of Lombardy (Italy). Biomass and Bioenergy, 34: 474-482.

Cespi D, Passarini F, Ciacci L, et al. (2014). Heating systems LCA: Comparison of biomass-based appliances. The International Journal of Life Cycle Assessment, 19: 89-99.

Collins L (2012). Predicting annual energy consumption with thermal simulation: a UK perspective on mitigation of risks in estimation and operation. Building Simulation, 5: 117-125.

Cóstola D, Blocken B, Hensen JLM (2009). Overview of pressure coefficient data in building energy simulation and airflow network programs. Building and Environment, 44: 2027-2036.

De Carli M, Marigo M, Zulli F, et al. (2020). Action D3. Bilancio energetico del settore residenziale-Report sui consumi dei vettori energetici impiegati nel riscaldamento delle abitazioni del Bacino Padano. Available at https://www.lifeprepair.eu/wp-content/ uploads/2020/10/D3_Report-sul-bilancio-energetico_Rev3_per_ pubblicazione.pdf (in Italian)

Dols WS, Polidoro BJ (2015).CONTAM user guide and program documentation. Version 3.2. NIST Technical note 1887. Available at: http://dx.doi.org/10.6028/NIST.TN.1887

Duanmu L, Yuan P, Wang Z, Xu C (2017). Heat transfer model of hot-wall Kang based on the non-uniform Kang surface temperature in Chinese rural residences. Building Simulation, 10: 145-163.

Elnakat A, Gomez JD (2016). The flame dilemma: A data analytics study of fireplace influence on winter energy consumption at the residential household level. Energy Reports, 2: 14-20.

European Commission (2019). The European Green Deal. Available at https://ec.europa.eu/info/sites/default/files/european-greendeal-communication_en.pdf. Accessed 14 Sept 2021.

European Committee for Standardization (2006). EN 14785:2006, Residential space heating appliances fired by wood pellets. Requirements and test methods, European Standard.

European Committee for Standardization (2008). EN 15603:2008, Energy performance of buildings-Overall energy use and definition of energy ratings, European Standard.
European Committee for Standardization (2017). EN 15316:2017, Heating systems in building. Method for calculation of system energy requirements and system efficiencies-Part 1: General and energy performance expression, European Standard.

European Committee for Standardization (2018). EN 16510:2018, Residential solid fuel burning appliances-Part 1: General requirements and test methods, European Standard.

European Committee for Standardization (2019). EN 16798-1:2019, Energy performance of buildings-Ventilation of buildingsPart 1: Indoor environmental input parameters for design and assessment of energy performance of buildings addressing indoor air quality, thermal environment, lighting and acoustics, European Standard.

European Parliament and Council (2018). On the promotion of the use of energy from renewable sources (Directive 2018/2001). Official Journal of the European Union. 82-209. Available at https://eur-lex.europa.eu/legal-content/EN/TXT/PDF/?uri=CELEX: 32018L2001\&from $=$ EN.

Eurostat (2018). Energy consumption in households. Available at https://ec.europa.eu/eurostat/statistics-explained/index.php?title= Energy_consumption_in_households\#Energy_products_used_in_ the_residential_sector. Accessed 13 Sept 2021.

Feist W, Schnieders J, Dorer V, et al. (2005). Re-inventing air heating: Convenient and comfortable within the frame of the Passive House concept. Energy and Buildings, 37: 1186-1203.

Fine JP, Gray J, Tian X, et al. (2020). An investigation of alternative methods for determining envelope airtightness from suite-based testing in multi-unit residential buildings. Energy and Buildings, 214: 109845 .

Francescato V, Rossi D (2019). Rapporto statistico AIEL 2019 Evoluzione del consumo di biocombustibili e delle emissioni della combustione in Italia, a scala domestica e commerciale. (In Italian)

Fritsche UR, Greß H-W (2015). Development of the Primary Energy Factor of Electricity Generation in the EU-28 from 2010-2013. International Institute for Sustainability Analysis and Strategy (IINAS). Available at https://www.ehpa.org/fileadmin/red/03. Media/03.02_Studies_and_reports/2015_IINAS_PEF_EU-28_ Electricity_2010-2013.pdf.

Gauthier G, Avagianos I, Calderón C, et al. (2020). Report Pellets. Bioenergy Europe. Available at https://bioenergyeurope.org/ article.html/268. Accessed 13 Sept 2021.

Georges L, Novakovic V (2012). On the integration of wood stoves for the space-heating of passive houses: Assessment using dynamic simulation. In: Proceedings of the First Building Simulation Optim Conference.

Georges L, Skreiberg $\varnothing$, Novakovic V (2014). On the proper integration of wood stoves in passive houses under cold climates. Energy and Buildings, 72: 87-95.

Haller MY, Paavilainen J, Konersmann L, et al. (2011). A unified model for the simulation of oil, gas and biomass space heating boilers for energy estimating purposes. Part I: Model development. Journal of Building Performance Simulation, 4: 1-18.

Harkouss F, Fardoun F, Biwole PH (2018). Optimization approaches and climates investigations in NZEB-A review. Building Simulation, 11: 923-952. 
Heiselberg P (2006). Modelling of natural and hybrid ventilation. DCE Lecture notes No. 4. Department of Civil Engineering, Aalborg University.

Holst S (1996). TRNSYS-Models for radiator heating systems.

Italian Organisation for Standardisation (2012). UNI/TS 11300-4, Energy performance of buildings, Part 4: Renewable energy and other generation systems for space heating and domestic hot water production. (in Italian)

Italian Organisation for Standardisation (2014). UNI/TR 11552, Opaque envelope components of buildings, Thermo-physical parameters. (in Italian)

ISTAT (2011). $15^{\circ}$ Censimento Generale della Popolazione e delle Abitazioni. National Institute of Statistics (ISTAT). Available at http://dati-censimentopopolazione.istat.it/Index.aspx. Accessed 1 Jun 2020. (in Italian)

ISTAT (2013). Censimento sui Consumi Energetici delle Famiglie. National Institute of Statistics (ISTAT). Available at: https:// www.istat.it/it/archivio/58343. Accessed 14 Sept 2021. (in Italian)

Jenkins D, Jackson F (2010). Wood pellet heating systems: The Earthscan expert handbook on planning, design and installation. Available at https://doi.org/10.4324/9781849774963.

Klein SA, Beckman WA, Mitchell JW, et al. (2014). TRNSYS 17, a TRaNsient SYstem Simulation program: vol. 4, Mathematical Reference. Available at http://web.mit.edu/parmstr/Public/ TRNSYS/04-MathematicalReference.pdf.

Krarouch M, Ruesch F, Hamdi H, et al. (2020). Dynamic simulation and economic analysis of a combined solar thermal and pellet heating system for domestic hot water production in a traditional Hammam. Applied Thermal Engineering, 180: 115839.

Kristjansson K, Næss E, Skreiberg Ø (2016). Dampening of wood batch combustion heat release using a phase change material heat storage: Material selection and heat storage property optimization. Energy, 115: 378-385.

Lamberg H, Sippula O, Tissari J, et al. (2017). Operation and emissions of a hybrid stove fueled by pellets and $\log$ wood. Energy \& Fuels, 31: 1961-1968.

Li Q, Jiang J, Wang S, et al. (2017). Impacts of household coal and biomass combustion on indoor and ambient air quality in China: Current status and implication. Science of the Total Environment, 576: 347-361.

Li G, Zhang J, Li H, et al. (2021). Towards high-quality biodiesel production from microalgae using original and anaerobicallydigested livestock wastewater. Chemosphere, 273: 128578.

McDowell TP, Emmerich S, Thornton JW, et al. (2003). Integration of airflow and energy simulation using CONTAM and TRNSYS. ASHRAE Transactions, 109(2): 757-770.

Ng LC, Musser A, Persily AK, et al. (2013). Multizone airflow models for calculating infiltration rates in commercial reference buildings. Energy and Buildings, 58: 11-18.

Oehler H, Mark R, Hartmann H, et al. (2016). Development of a test procedure to reflect real life operation of pellet stoves. In: Proceedings of the 24th European Biomass Conference and Exhibition, Amsterdam, The Netherlands.
Patti S, Pillon S, Intini B, et al. (2020). Action D3. Wood consumption estimation in the Po Valley-Report on the survey to estimate woody biomasses consumption in households. Available at http://www.lifeprepair.eu/wp-content/uploads/2017/06/D3_Reporton-woody-biomasses-consumption-in-households_01feb2020-1.pdf

Pedersen TH, Hedegaard RE, Kristensen KF, et al. (2019). The effect of including hydronic radiator dyamics in model predictive control of space heating. Energy and Buildings, 183: 772-784.

Persson T, Nordlander S, Rönnelid M (2005). Electrical savings by use of wood pellet stoves and solar heating systems in electrically heated single-family houses. Energy and Buildings, 37: 920-929.

Persson T, Fiedler F, Nordlander S, et al. (2009). Validation of a dynamic model for wood pellet boilers and stoves. Applied Energy, 86: 645-656.

Persson T, Wiertzema H, Win KM, et al. (2019). Modelling of dynamics and stratification effects in pellet boilers. Renewable Energy, 134: 769-782.

Petrocelli D, Lezzi AM (2014). Modeling operation mode of pellet boilers for residential heating. Journal of Physics: Conference Series, 547: 012017.

Quinteiro P, Tarelho L, Marques P, et al. (2019). Life cycle assessment of wood pellets and wood split logs for residential heating. Science of the Total Environment, 689: 580-589.

Risberg D, Risberg M, Westerlund L (2016). CFD modelling of radiators in buildings with user-defined wall functions. Applied Thermal Engineering, 94: 266-273.

Schumack M (2016). A computational model for a rocket mass heater. Applied Thermal Engineering, 93: 763-778.

Seem JE (1987). Modelling of heat transfer in buildings. Ph.D Thesis, University of Wisconsin Madison, USA.

Skreiberg Ø, Georges L (2018). Transient heat production and release profiles for wood stoves. Chemical Engineering Transactions, 65: 223-228.

Swami MV, Chandra S (1988). Correlations for pressure distribution on buildings and calculation of natural-ventilation airflow. ASHRAE Transactions, 94(1): 243-266.

TESS (2012). TESS component libraries - General description. Thermal Energy Storage Specialists (TESS). Available at: http://www.trnsys.com/tess-libraries/. Accessed 13 Sept 2021.

Tol Hİ (2020). Improved space-heating radiator model: Focus on set-back operation, radiator over-dimensioning, and add-on fans. Building Simulation, 13: 317-334.

Xu B, Fu L, Di H (2008). Dynamic simulation of space heating systems with radiators controlled by TRVs in buildings. Energy and Buildings, 40: 1755-1764.

Yu K, Cao Z, Liu Y (2017). Research on the optimization control of the central air-conditioning system in university classroom buildings based on TRNSYS software. Procedia Engineering, 205: 1564-1569.

Zhao N, Li B, Li H, et al. (2021). The potential co-benefits for health, economy and climate by substituting raw coal with waste cooking oil as a winter heating fuel in rural households of Northern China. Environmental Research, 194: 110683. 